\title{
AGUA, RECURSO ESTRATÉGICO
}

\author{
PODER, CONFLICTO SOCIAL Y \\ POLÍTICA PÚBLICA EN \\ LA SIERRA SUR DEL PERÚ
}

Andrés Corsino Estrada Zúñiga ${ }^{1}$

$E_{R}$ estudio investigación titulada "Agua, Recurso Estratégico: Poder, Conflicto Social y Política Pública en la Sierra Sur del Perú", ha tomado como estudios de caso la cuenca del río Huatanay - Vilcanota de la Región Cusco y la cuenca del río Tambo, entre las regiones de Moquegua y Arequipa. Como objetivo se plantea contribuir al diseño de una estrategia de gestión integrada del agua para que las poblaciones de la sierra y sus organizaciones de usuarios puedan integrarse a un proceso de desarrollo regional sustentable que les permita protegerse de las agresiones sociales, culturales y económicas. El estudio se realizó en dos etapas la primera entre el 2008 al 2011 y la segunda etapa el 2015.

Se plantea la siguiente hipótesis: las políticas públicas y estrategias basadas en la Gestión Integrada de los Recursos Hídricos (GIRH), deben considerar:

-i) La capacidad de los actores locales para participar en el diseño de instrumentos y estrategias de solución de conflictos.

-ii) El funcionamiento de la institucionalidad y la situación de equilibrio ambiental de los recursos hídricos.

-iii) La asignación o acceso equitativo al agua para sus múltiples usos, 1 Doctor en Ingeniera. Centro de Estudios Regionales Andinos Bartolomé de las Casas. Universidad Nacional de San Antonio
Abad del Cusco. E-mail: andres.estrada@unsaac.edu.pe 
independiente del tamaño de las actividades económico productivas o de los ingresos de las familias.

El estudio llegó a las siguientes conclusiones:

-i) El rol de los actores locales es determinante en el desarrollo de herramientas de solución de conflictos, por lo tanto, cualquier estrategia basada en la GIRH debe considerarlos. A su vez, hay que tomar en cuenta el trabajo necesario para consolidar la institucionalidad y asegurar el uso

"En el sur del Cusco, este modelo ha encontrado una sociedad rural con capacidad de movilización $y$ fuerza contestataria, basada en un nuevo paradigma de desarrollo."

sustentable del agua a través de su asignación equitativa y cuidado ambiental.

-ii) Los estudios de caso y la situación actual de desarrollo de políticas y estrategias en torno al agua, reafirman la importancia de considerar los puntos planteados en la hipótesis para que se puedan resolver los conflictos por el agua y las comunidades se integren a un verdadero proceso de desarrollo regional sustentable.

-iii) El modelo económico actual del país, de tipo neoliberal, está incrementando los conflictos por acceso y distribución a los recursos naturales y especialmente al agua, lo que se refleja en los estudios de caso. En el sur del Cusco, este modelo ha encontrado una sociedad rural con capacidad de movilización y fuerza contestataria, basada en un nuevo paradigma de desarrollo y que tiene como fundamento la protección de los recursos naturales y el respeto de los valores, los principios y de la cultura local ancestral.

-iv) La política nacional ajustada al modelo planteado por el gobierno central, es vertical, no promueve la cultura de la consulta y el diálogo; desde el gobierno se promueven políticas públicas y normativas que protegen las inversiones extranjeras y, para las comunidades campesinas se promueven políticas sociales y alimentarias. Sin embargo, los conflictos y sus estrategias de resolución contribuyeron en el proceso de descentralización en la gestión del agua a través de un proceso de construcción de normas que va de abajo hacia arriba.

- v) Las estrategias y herramientas utilizadas para la resolución de los conflictos en las cuencas de Tambo y Huatanay Vilcanota, fueron recogidas por los representantes de los usuarios de agua, por los parlamentarios y por el propio gobierno para ser consideradas como aportes al debate de la nueva institucionalidad del agua en el Perú, las mismas que en marzo de 2009 se plasmaron en la Ley de Recursos Hídricos, ํ 29338.

—vi) En los últimos años, en el Perú y en especial en la sierra sur, se implementan programas de fortalecimiento de capacidades para los actores locales comunitarios con la finalidad de mejorar su participación en los procesos de planificación del territorio y los recursos naturales con énfasis en el agua. Estos programas se llevan a cabo gracias al 
aporte de las ONGs y la cooperación internacional.

- v) La contaminación del agua por uso humano, industrial y extractivo, ha

incidido directamente sobre su calidad.

El impacto directo se da en las poblaciones que aguas abajo usan el recurso para la agricultura, por ello, en las cuencas de Vilcanota y Tambo se evidencia bajas condiciones de salud en la población, situación que disminuye su capacidad laboral y productiva.

Asimismo, se plantean las siguientes recomendaciones:

-i) Fortalecer las capacidades de los actores para generar espacios de diálogo en condiciones equilibradas, implementando un programa de desarrollo de capacidades en diferentes niveles (promotores, líderes, técnicos y políticos) para crear una masa crítica con capacidad de: responder a los futuros conflictos e implementar estrategias de gestión integrada del agua en el marco

de la nueva Ley de Recursos Hídricos, $\mathrm{N}^{\circ}$

29388.

-ii) El programa de desarrollo de capacidades debe incluir acciones de sensibilización en las ciudades, como Cusco y otras de crecimiento intermedio, con la finalidad de construir una nueva cultura de uso del agua; ello significaría además el pago

de una tasa para solventar los procesos de conservación y producción de agua en las cabeceras de cuenca.
Las empresas extractivas que operan en estas frágiles zonas deben pagar una tasa especial.

-iii) Se recomienda un proceso de acompañamiento, fortalecimiento y monitoreo de la nueva Ley de Recursos Hídricos, con la finalidad de promover la regionalización hidrográfica por cuenca propuesta por la Autoridad Nacional del Agua. iv) Promover políticas locales y regionales de protección de los recursos naturales con énfasis en los recursos hídricos. v) Complementar conceptos y herramientas del enfoque de Gestión Integrada de Recursos Hídricos con la Justicia Hídrica, relacionada al acceso equitativo y la gobernabilidad del agua.

- vi) Para la cuenca del Tambo se recomienda ejecutar estudios que permitan profundizar el análisis de los impactos y su relación con los grados de desarrollo sustentable de la cuenca. Al mismo tiempo, se recomienda a los sectores de salud y agricultura implementar sistemas de información que permitan registrar adecuadamente el desenvolvimiento de los indicadores.

- vii) Evaluar el PROFODUA como herramienta válida para ser aplicada en distintos contextos (sierra, costa y selva) y así tener una visión global con la finalidad de proponerla como política pública nacional que promueve y fortalece la estrategia nacional de agua. viii) Implementar un sistema de monitoreo de conflictos por el agua desde la Defensoría del Pueblo y no generalizarlos bajo el rubro de "conflictos socio ambientales".

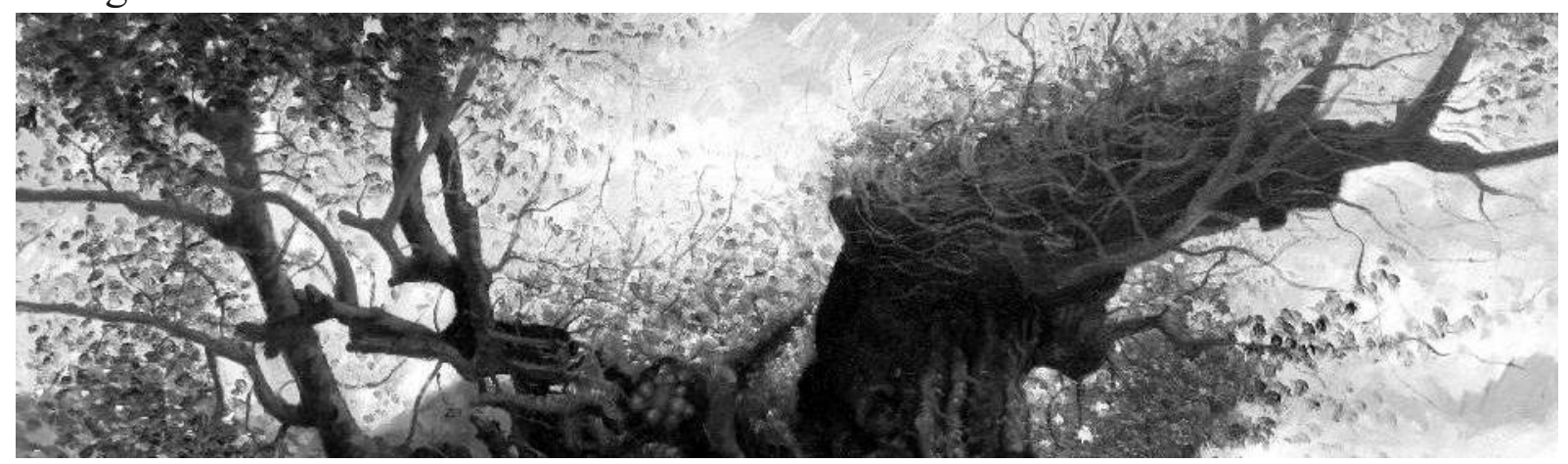

